\title{
Effect of thyroglobulin autoantibodies on the metabolic clearance of serum thyroglobulin
}

\author{
Francesco Latrofa, $\mathrm{MD}^{1}$, Debora Ricci, $\mathrm{PhD}^{1}$, Sara Bottai, $\mathrm{MD}^{1}$, Federica Brozzi ${ }^{1}$, Luca \\ Chiovato ${ }^{2}$, Paolo Piaggi, $\mathrm{PhD}^{3}$, Michele Marinò, $\mathrm{MD}^{1}$, Paolo Vitti, $\mathrm{MD}^{1}$ \\ ${ }^{1}$ Endocrinology Unit I, Department of Clinical and Experimental Medicine, \\ University Hospital of Pisa, Italy \\ ${ }^{2}$ Unit of Internal Medicine and Endocrinology, Fondazione Salvatore Maugeri, University of \\ Pavia, Italy \\ ${ }^{3}$ Phoenix Epidemiology and Clinical Research Branch, National Institute of Diabetes and \\ Digestive and Kidney Diseases, National Institutes of Health, Phoenix, AZ
}

\section{Contact information}

Francesco Latrofa, MD, Endocrinology Unit, Via Paradisa 2, 56124, Pisa, Italy; francesco.latrofa@unipi.it

Debora Ricci, PhD, Endocrinology Unit, Via Paradisa 2, 56124, Pisa, Italy; debora.ricci.wbem@alice.it

Sara Bottai, MD, Endocrinology Unit, Via Paradisa 2, 56124, Pisa, Italy; sarabottai@hotmail.it

Federica Brozzi, Endocrinology Unit, Via Paradisa 2, 56124, Pisa, Italy;federicabrozzi@yahoo.it

Luca Chiovato, MD; Unit of Internal Medicine and Endocrinology, Fondazione Salvatore Maugeri I.R.C.C.S., Via Maugeri 10, 27100, Pavia, Italy; luca.chiovato@fsm.it

Paolo Piaggi, PhD, Phoenix Epidemiology and Clinical Research Branch, National Institute of Diabetes and Digestive and Kidney Diseases, National Institutes of Health, Phoenix, AZ, USA; paolo.piaggi@gmail.com 
Page 2 of 21

Michele Marinò, MD, Endocrinology Unit, Via Paradisa 2, 56124, Pisa Italy;michele.marino@med.unipi.it

Paolo Vitti, MD, Endocrinology Unit, Via Paradisa 2, 56124, Pisa Italy;

paolo.vitti@med.unipi.it

Running title: Thyroglobulin autoantibodies and clearance of thyroglobulin 


\section{Abstract}

Background: To establish whether thyroglobulin autoantibodies (TgAb) influence the metabolic clearance of thyroglobulin $(\mathrm{Tg})$ in humans, we correlated serum $\mathrm{Tg}$ and $\mathrm{TgAb}$ shortly after ${ }^{131}$ I treatment.

Methods: Samples were collected from 30 consecutive patients undergoing ${ }^{131}$ I activity for Graves' hyperthyroidism at the time of treatment and every 15 days thereafter, up to 90 days. $\operatorname{Tg}$ and $\operatorname{TgAb}$ were measured by immunometric assays (functional sensitivities: 0.1 $\mathrm{ng} / \mathrm{mL}$ and $8 \mathrm{IU} / \mathrm{mL})$.

Results: $\operatorname{Tg}$ was detectable in all patients at day $0 . \mathrm{Tg}$ concentrations rose from $33.2 \mathrm{ng} / \mathrm{mL}$ (17.8-61.0) at day 0 to $214.6 \mathrm{ng} / \mathrm{mL}(116.9-393.4)$ at day 30 and then steadily decreased, reaching the lowest concentration at day $90(10.9$ [5.5-20.9] $\mathrm{ng} / \mathrm{mL})$. Compared to their levels at day $0(23.6$ [10.5-52.9] IU/mL), TgAb remained stable through day 15 and then gradually increased up to $116.6(51.9-262.2) \mathrm{IU} / \mathrm{mL}$ at day 90 . Patients were then split into two groups, according to their TgAb status at day 0: undetectable ( $<8 \mathrm{IU} / \mathrm{mL}, 9$ patients) or detectable ( $\geq 8,21$ patients) TgAb. Compared to the other cohort, patients with detectable TgAb showed significantly lower Tg concentrations at day 0 (20.3 [10.1-40.2] vs. 101.8 [36.6-279.8] ng/mL), similar at day 15, lower levels at day 30 (146.5 [74.3-287.8] vs. 514.8 [187.8-1407.9] ng/mL), at day 45 (87.5 [43.1-176.6] vs. 337.9 [120.1-947.0] ng/mL), at day $60(61.6$ [31.0-121.4] vs. 255.8 [79.0-823.8] ng/mL) and at day 75 (24.5 [11.9-49.2] vs. 249.5 [63.5-971.1] ng/mL), and similar levels at day 90. Patients with detectable TgAb showed a lower (182.5 [92.0-361.0] vs. 514.8 [187.8-1407.9] ng/mL) and an earlier (day 15 vs. day 30) peak of $\mathrm{Tg}$. The mean $\mathrm{Tg}$ concentration was lower in patients with detectable TgAb than in those with undetectable TgAb (AUC: $17340 \pm 16481 \mathrm{ng} / \mathrm{mL}$ vs. $36883 \pm 44625$ $\mathrm{ng} / \mathrm{mL})(\mathrm{p}=0.02)$.

Conclusions: $\operatorname{TgAb}$ influence the changes in Tg concentrations observed immediately after ${ }^{131}$ I treatment, inducing lower levels and an earlier peak of $\mathrm{Tg}$. These observations indicate that $\operatorname{TgAb}$ significantly influence the metabolic clearance of $\mathrm{Tg}$, supporting the concept that their interference in the measurement of $\mathrm{Tg}$ is mainly due to an in vivo effect. 
Introduction

Serial measurement of serum thyroglobulin $(\mathrm{Tg})$, which is produced by normal follicular cells and follicular cell-derived differentiated thyroid carcinoma (DTC) as well, is a cornerstone in the follow-up of DTC (1). However, coexistent serum Tg autoantibodies (TgAb), which are positive in $7.5-25 \%$ of DTC patients, significantly impair the reliability of serum $\mathrm{Tg}$ measurements $(2,3,4)$. When measured by immunometric assays (IMAs), the most sensitive methods currently available, $\mathrm{Tg}$ is often lower than expected or even undetectable in sera with detectable $\operatorname{TgAb}(5,6,7)$. This effect is usually ascribed to analytical interference i.e., the ability of serum $\operatorname{TgAb}$ to hide $\mathrm{Tg}$ epitopes from the binding of the antibodies used in the assay $(3,8)$. However, all methods proposed to eliminate analytical interference, including most recently tandem mass spectrometry, have been proved unsuccessful (9). In addition, we have recently observed that TgAb interference in the detection of Tg by IMA is much more significant in vivo (when Tg is measured in sera from patients with $\operatorname{TgAb}$ ) than in vitro (when $\mathrm{Tg}$ is recovered after its incubation with TgAb positive samples) (7). This body of evidence suggests that other mechanisms are responsible for TgAb interference. The enhanced metabolic clearance of Tg induced by TgAb, which was shown in experimental autoimmune thyroiditis, is the most likely mechanism involved (10).

To establish whether TgAb influence Tg metabolic clearance in humans, we decided to correlate serum $\mathrm{Tg}$ and $\mathrm{TgAb}$ shortly after ${ }^{131} \mathrm{I}$ treatment for Graves' hyperthyroidism. ${ }^{131}$ I damages thyroid cells and releases Tg from thyroid follicules, causing a transient rise in serum $\operatorname{Tg}(11-14)$.

\section{Materials and Methods}

\section{Study group}

Sera samples were collected, after obtaining signed informed consent, from 30 consecutive patients undergoing treatment with ${ }^{131}$ I (555 MBq) because of Graves' hyperthyroidism at the Endocrinology Unit, University Hospital of Pisa, Italy, between February 2013 to September 2013. The institutional review board of the Endocrinology Unit approved the study. All patients had been treated with methimazole, which was 
discontinued 5-7 days before ${ }^{131}$ I treatment. Samples were collected at the time of ${ }^{131}$ I treatment (day 0) (30 patients), 15 days (25 patients), 30 days (28 patients), 45 days (24 patients), 60 days (24 patients), 75 days (21 patients) and 90 days (27 patients) afterwards. FT4, FT3, TSH, Tg, TgAb, thyroperoxidase autoantibodies (TPOAb) and TSH-receptor autoantibodies (TRAb) were determined at all time points. Thyroid ultrasound was performed at day 0 , day 30, day 60 and day 90 . Treatment with methimazole was restarted in patients showing persistent thyrotoxicosis, while treatment with levothyroxine (L-T4) was initiated when patients became hypothyroid. Although they had mild Graves' ophthalmopathy, all patients were treated with oral prednisone (20-30 mg/daily; 0.4-0.5 $\mathrm{mg} / \mathrm{kg}$ body weight daily, which was then tapered and discontinued within three months), to prevent the possible exacerbation of the eye condition.

\section{Serum assays}

FT4 and FT3 were measured by free T4 and free T3 reagent packs (Ortho-clinical Diagnostics Inc., Rochester, NY, USA) (reference range $7.0-17.0 \mathrm{pg} / \mathrm{mL}$ and $2.7-5.7 \mathrm{pg} / \mathrm{mL}$, respectively). TSH was determined using Immulite 2000 (Euro/DPC, Gwynedd, UK) (reference range 0.4-3.6 $\mu \mathrm{U} / \mathrm{mL}$ ). Tg was measured by an IMA (Access Thyroglobulin assay; Beckman Coulter, Inc., Fullerton CA) (functional sensitivity $0.1 \mathrm{ng} / \mathrm{mL}$ ). TgAb were measured using AIA-Pack $2000 \mathrm{TgAb}$ (functional sensitivity $8 \mathrm{IU} / \mathrm{mL}$ ), positive cut-off 30 $\mathrm{IU} / \mathrm{mL}$ ) and TPOAb using AIA-Pack 2000 TPOAb (analytical sensitivity $3 \mathrm{IU} / \mathrm{mL}$, positive cutoff $10 \mathrm{lU} / \mathrm{mL}$ ), both by Tosoh Corporation, Tokyo, Japan. TRAb were measured using the Brahms TRAk human RIA assay (Hennigsdorf, Germany) (analytical sensitivity $1 \mathrm{lU} / \mathrm{mL}$, cutoff $1.5 \mathrm{IU} / \mathrm{mL})$.

\section{Neck ultrasound}

Neck ultrasound was performed using a Technos (Esaote Biomedica, Genova, Italy) ultrasound with a $7.5 \mathrm{MHz}$ linear transducer. The volume of each thyroid lobe was calculated with the ellipsoid formula: width $(\mathrm{mm}) \times$ length $x$ thickness $\times 0.52(\mathrm{~mL})$. 


\section{Statistical Analysis}

Descriptive data are presented as median and interquartile range (IQR: $25^{\text {th }}-75^{\text {th }}$ percentiles). Repeated measures mixed models were used to analyze the time courses of $\mathrm{Tg}$ and TgAb levels over time using an autoregressive covariance structure [i.e., AR]. Prior to analysis, both $\operatorname{Tg}$ and $\operatorname{TgAb}$ were log-transformed to approximate a normal distribution, and results are reported as geometrical means with $95 \%$ confidence interval $(95 \% \mathrm{Cl})$. The Spearman's $(\rho)$ correlation coefficient was employed to assess the association between $\operatorname{Tg}$ and $\operatorname{TgAb}$ at each time point. Statistical significance was considered for $P$-values $<0.05$.

\section{Results}

Changes in concentrations of thyroid hormones and TSH, levels of TPOAb and TRAb and thyroid volume

Table 1 shows the changes in the concentrations of FT4, FT3 and TSH, the levels of TPOAb and TRAb, and the thyroid volumes after ${ }^{131}$ I treatment. At the end of the study, 21 patients were being treated with L-T4 because of hypothyroidism, while 3 patients required treatment with methimazole because of transient thyrotoxicosis during the study. The levels of TPOAb and TRAb progressively rose while the thyroid volumes gradually decreased after ${ }^{131}$ I treatment.

\section{Changes in Tg concentrations and TgAb levels}

$\mathrm{Tg}$ was detectable in all patients at day 0. The concentrations of $\mathrm{Tg}$ rose from 33.2 $(17.8-61.0) \mathrm{ng} / \mathrm{mL}$ (geometric mean and $95 \% \mathrm{Cl}$ ) at day 0 to $214.6(116.9-393.4) \mathrm{ng} / \mathrm{mL}$ at day 30 and then steadily decreased, and they were substantially lower (10.9 [5.5-20.9] $\mathrm{ng} / \mathrm{mL}$ ) at day 90 than at day 0 (fig. 1).

Compared to their levels at day 0 (23.6 [10.5-52.9] IU/mL [geometric mean and 95\% Cl]), TgAb remained stable through day $30(24.1[10.8-54.1] \mathrm{IU} / \mathrm{mL})$, and then gradually increased up to 116.6 (51.9-262.2) IU/mL at day 90 (fig. 1). 


\section{Correlation between $\operatorname{Tg}$ concentrations and $\operatorname{TgAb}$ levels}

A significant inverse correlation was observed between $\operatorname{TgAb}$ levels and $\mathrm{Tg}$ concentrations at all time points, except at day 15 (fig. 2).

\section{Changes in Tg concentration according to the initial TgAb level}

Patients were split into two groups, according to their $\operatorname{TgAb}$ status at day 0 : undetectable (<8 IU/mL) (9 patients) or detectable ( $\geq 8 \mathrm{IU} / \mathrm{mL}$ ) (21 patients). Thyroid volume at day 0 was similar in the two groups: $16.0 \pm 8.0 \mathrm{~mL}$ (median and IQR) in patients with undetectable TgAb vs. $19 \pm 9.8 \mathrm{~mL}$ in patients with detectable TgAb ( $p=0.47)$. Neither age nor thyroid function influenced $\mathrm{Tg}$ levels in patients with undetectable $\operatorname{TgAb}$.

Compared to those with undetectable TgAb, patients with detectable TgAb showed significantly lower Tg concentrations at day 0 (20.3 [10.1-40.2] [geometric mean and 95\% $\mathrm{Cl}]$ vs. 101.8 [36.6-279.8] ng/mL), similar levels at day 15 (182.5 [92.0-361.0] vs. 247.5 [85.3-714.6] ng/mL), lower levels at day 30 (146.5 [74.3-287.8] vs. 514.8 [187.8-1407.9] $\mathrm{ng} / \mathrm{mL})$, at day 45 (87.5 [43.1-176.6] vs. 337.9 [120.1-947.0] ng/mL), at day 60 (61.6 [31.0121.4] vs. 255.8 [79.0-823.8] ng/mL) and at day 75 (24.5 [11.9-49.2] vs. 249.5 [63.5-971.1] $\mathrm{ng} / \mathrm{mL}$ ), and similar levels at day 90 (7.3 [3.2-15.4] vs. 26.7 [9.1-74.6] ng/mL) (fig. 3). Compared to patients with undetectable $\operatorname{TgAb}$, patients with detectable TgAb showed a lower (182.5 [92.0-361.0] vs. 514.8 [187.8-1407.9] $\mathrm{ng} / \mathrm{mL}$ ) and earlier peak (day 15 vs. day 30) of Tg. In both groups, the lowest Tg concentrations were observed at day 90 (7.3 [3.215.4] and 26.7 [9.1-74.6] ng/mL).

The overall (from day 0 to day 90) Tg concentration was more than 2-times higher in patients with undetectable $\operatorname{TgAb}$ than in those with detectable TgAb (fold change=2.82, $\mathrm{p}=0.009$ by mixed models) (fig. $4 \mathrm{a}$ and $4 \mathrm{~b}$ ). Accordingly, the mean 90-day AUC of $\mathrm{Tg}$ concentrations was higher in patients with undetectable $\operatorname{TgAb}(36883 \pm 44625 \mathrm{ng} / \mathrm{mL})$ (mean and $95 \% \mathrm{Cl})$ than in patients with detectable $\operatorname{TgAb}(17340 \pm 16481 \mathrm{ng} / \mathrm{mL})(\mathrm{p}=0.02)$ (fig. $4 \mathrm{c})$.

\section{Discussion}

$\mathrm{Tg}$ is the specific marker of thyroid tissue, being produced by normal thyroid follicular cells and differentiated cancers originating from follicular cells. Along with 
ultrasound and imaging, follow-up of DTC patients consists in serial measurements of $\mathrm{Tg}$ (1). A major drawback in the measurement of $\mathrm{Tg}$ is interference from coexistent $\mathrm{TgAb}$ $(6,15,16)$. TgAb are a marker of autoimmune thyroid diseases (17-20) and 7.5-25\% of DTC patients show positive TgAb (2-4), as expression of an associated autoimmune thyroid disease or an immune reaction to thyroid carcinoma $(6,21,22)$. Tg concentrations and the heterogeneity of $\mathrm{Tg}$ and $\mathrm{TgAb}$ are factors contributing to the discordant results of $\mathrm{Tg}$ measurements in TgAb positive patients $(5,6,7,9,23,24)$.

IMAs are the most sensitive methods for Tg measurement currently available $(1,9)$. In the presence of $\operatorname{TgAb}, \mathrm{Tg}$ values are lower than expected or even undetectable when measured by IMAs $(5,6,24)$. These results are usually considered as falsely low Tg results. $\mathrm{Tg}$ radioimmunoassays, proposed as methods that are more resistant to TgAb interference, can yield falsely positive or falsely negative $\mathrm{Tg}$ results, depending on $\mathrm{Tg}$ concentrations and $\operatorname{TgAb}$ levels $(5,6,8,9,25,26)$. The two other methods suggested in the past as resistant to $\mathrm{TgAb}$ interference, namely $\mathrm{Tg}$ recovery and $\mathrm{Tg}$ measurement by epitope-specific monoclonal TgAb, did not succeed in solving the problem $(2,15)$. Tandem mass spectrometry, the latest methodology proposed, seems of limited efficacy as well $(8,9,27)$. According to many recovery studies showing interference related to epitope masking (28), we have recently confirmed that interference of $\operatorname{TgAb}$ in the measurement of $\mathrm{Tg}$ in vitro depends on both the Tg concentration and the TgAb levels (7). The relative contribution of in vitro (masking of epitopes) versus in vivo (TgAb- mediated Tg clearance) factors responsible for $\operatorname{TgAb}$ interference with $\mathrm{Tg}$ measurements may be variable and patient-specific.

An accelerated metabolic clearance of $\operatorname{Tg}$ in $\operatorname{TgAb}$ positive animals due to its greater elimination from the bloodstream was demonstrated in experimental autoimmune thyroiditis (10). Some indirect clinical evidence suggests that this phenomenon plays a role in humans as well $(6,29)$.

Since ${ }^{131}$ I induces a rise in $\operatorname{Tg}(11-14)$, we decided to correlate $\operatorname{Tg}$ and TgAb concentrations in patients shortly after ${ }^{131}$ I treatment for Graves' hyperthyroidism in order to evaluate the influence of $\operatorname{TgAb}$ on the metabolic clearance of $\mathrm{Tg}$ in humans. After ${ }^{131}$ I 
therapy, both TPOAb and TRAb rose from day 60 while thyroid volumes decreased from day 30 onward. As an effect of the damage of thyroid cells and its release into the bloodstream, $\mathrm{Tg}$ rose, reaching a peak at day 30 , then it fell to reach its lowest concentration at day 90 . TgAb remained stable through day 30 and then rose, peaking at day 90. Tg concentrations and $\operatorname{TgAb}$ levels were inversely correlated at almost all time points: the higher the $\operatorname{TgAb}$ values, the lower the $\mathrm{Tg}$ concentrations. The changes in $\mathrm{Tg}$ concentration were therefore specular to those in TgAb levels.

To better evaluate the in vivo effect of $\operatorname{TgAb}$, we then subdivided the patients into two groups, according to their initial TgAb status: undetectable or detectable. Although thyroid volume was similar in the two cohorts, at day $0 \mathrm{Tg}$ concentrations were significantly lower in the group with detectable $\operatorname{TgAb}$. At day $15, \mathrm{Tg}$ levels rose to a higher degree in the group with undetectable $\operatorname{TgAb}$, reaching concentrations that were comparable to the other group. At day 30, Tg concentrations continued to rise in the group with undetectable $\operatorname{TgAb}$, while it started to decline in the group with detectable $\operatorname{TgAb}$. The differences in $\mathrm{Tg}$ concentrations reflect two opposite events: the release into the bloodstream of $\mathrm{Tg}$ from the thyroid after ${ }^{131} \mathrm{I}$ damage and its enhanced metabolic clearance induced by TgAb. It is worth recalling that the levels of TgAb did not change up to day 30 and that day 15 was the only time point in which $\mathrm{Tg}$ concentrations and $\mathrm{TgAb}$ levels did not inversely correlate with each other. Consistent with the effect of $\operatorname{TgAb}$ on $\mathrm{Tg}$ clearance, from day 45 to day $75 \mathrm{Tg}$ concentrations were higher in the group with undetectable $\operatorname{TgAb}$ than in the other group. Therefore, patients with detectable $\operatorname{TgAb}$ showed a lower and earlier peak and a lower mean concentration of $\mathrm{Tg}$. At day 90, $\mathrm{Tg}$ levels were similar in the two groups because thyroid destruction by ${ }^{131}$ I was the predominant effect at this time point. Neither age nor thyroid function influenced Tg levels in patients with undetectable $\operatorname{TgAb}$. However, these observations need to be confirmed in a larger study group.

The changes in Tg concentrations and TgAb levels we have observed are similar to the effects previously reported in a small cohort of patients evaluated for 6 months after ${ }^{131}$ I treatment for Graves' hyperthyroidism (13). 
We could not calculate the half-life of $\mathrm{Tg}$ in our study because of the prolonged release of $\mathrm{Tg}$ into the bloodstream induced by ${ }^{131} \mathrm{I}$. The half-life of $\mathrm{Tg}$ has been estimated to range from 3.7 hours to 4.3 days in humans (30-34). Clearance of $\mathrm{Tg}$ from the circulation varies with the state of glycosylation, asialo-Tg being cleared more rapidly from the circulation of rats (half-life of 6-40 minutes) than its sialylated counterpart (half-life of 5.1 to 15 hours) (35). Also, binding of bovine asialo-Tg to thyroid and liver membrane preparations has been documented (36), and it has been shown that clearance of Tg from the circulation by the liver occurs by endocytosis in macrophages (37).

We have recently reported that the rise in TgAb IgG observed after ${ }^{131} \mathrm{I}$ treatment for Graves' hyperthyroidism is restricted to $\lg G 1$ and $\lg G 3$ (29). IgG3 and, to a lower extent, IgG1 are the strongest activators of the classical pathway of the complement pathway. The C3b fragments released after complement activation interact with CR1 on erythrocytes to take the immune complexes out of the plasma. In spleen and liver, the immune complexes are captured by complement and IgG receptors localized on the resident macrophage and dendritic cells. IgG1 and IgG3 show high-affinity binding to Fc?RI and IgG3 to FcyRIIIA. FcyRI and FcyRIIIA are stimulatory receptors, expressed on monocytes/macrophages. FcyRI and FcyRIIIA are also expressed in dendritic cells and NK cells, respectively. IgG1 bind also to FcRn, which is expressed on monocytes/macrophages, neutrophils and dendritic cells (38). Macrophages are the most efficient professional phagocytes and, when activated, internalize immune complexes. The rise in IgG1 and IgG3 levels seems to respond to the task of removing the large bulk of Tg released into the circulation after the thyroid damage induced by ${ }^{131} \mathrm{l}$.

The present findings, in addition to previous data, support the concept that, in patients with $\operatorname{TgAb}$, the lower than expected $\mathrm{Tg}$ concentrations observed when $\mathrm{Tg}$ is measured by IMA and tandem mass spectroscopy $(2,6,8,9,27)$ is mainly due to a truly low $\mathrm{Tg}$ concentration. In spite of its active secretion by thyroid tissue, serum $\mathrm{Tg}$ is low or undetectable because it is removed at a faster rate from the circulation when TgAb coexist. 
In conclusion, $\operatorname{TgAb}$ lessen the rise in $\mathrm{Tg}$ concentration that is induced by the thyroid damage due to ${ }^{131}$ I treatment. This observation indicates that TgAb interference on $\mathrm{Tg}$ measurements is mainly due to its ability to remove $\mathrm{Tg}$ from the circulation, supporting the role of $\operatorname{TgAb}$ in the metabolic clearance of $\mathrm{Tg}$. This consideration strongly supports the notion that the finding of undetectable Tg concentrations by IMA in DTC patients with coexistent $\operatorname{TgAb}$ is not due to mere analytical interference. It is foreseeable that any further attempt to overcome this limitation would prove unsuccessful.

\section{Acknowledgments}

These studies were supported by the grant "Rientro dei cervelli" n. 311 from MIUR and University of Pisa to Francesco Latrofa.

\section{Author Disclosure Statement}

The authors have nothing to disclose. 


\section{Reference List}

1. Haugen BR, Alexander EK, Bible KC, Doherty GM, Mandel SJ, Nikiforov YE, Pacini F, Randolph GW, Sawka AM, Schlumberger M, Schuff KG, Sherman SI, Sosa JA, Steward DL, Tuttle RM, Wartofsky L 20162015 American Thyroid Association Management Guidelines for Adult Patients with Thyroid Nodules and Differentiated Thyroid Cancer: The American Thyroid Association Guidelines Task Force on Thyroid Nodules and Differentiated Thyroid Cancer. Thyroid 26:1-133.

2. Mariotti S, Barbesino G, Caturegli P, Marino M, Manetti L, Pacini F, Centoni R, Pinchera A 1995 Assay of thyroglobulin in serum with thyroglobulin autoantibodies: an unobtainable goal? Journal of Clinical Endocrinology Metabolism 80:468-472.

3. Spencer CA, Takeuchi M, Kazarosyan M, Wang CC, Guttler RB, Singer PA, Fatemi S, LoPresti JS, Nicoloff JT 1998 Serum Thyroglobulin Autoantibodies: Prevalence, Influence on Serum Thyroglobulin Measurement, and Prognostic Significance in Patients with Differentiated Thyroid Carcinoma. Journal of Clinical Endocrinology Metabolism 83:11211127.

4. Chiovato L, Latrofa F, Braverman LE, Pacini F, Capezzone M, Masserini L, Grasso L, Pinchera A 2003 Disappearance of humoral thyroid autoimmunity after complete removal of thyroid antigens. Ann.Intern.Med. 139:346-351.

5. Spencer C, Petrovic I, Fatemi S 2011 Current Thyroglobulin Autoantibody (TgAb) Assays Often Fail to Detect Interfering TgAb that Can Result in the Reporting of Falsely Low/Undetectable Serum Tg IMA Values for Patients with Differentiated Thyroid Cancer. Journal of Clinical Endocrinology Metabolism 96:1283-1291.

6. Latrofa F, Ricci D, Montanelli L, Rocchi R, Piaggi P, Sisti E, Grasso L, Basolo F, Ugolini C, Pinchera A, Vitti P 2012 Lymphocytic Thyroiditis on Histology Correlates with Serum Thyroglobulin Autoantibodies in Patients with Papillary Thyroid Carcinoma: Impact on Detection of Serum Thyroglobulin. Journal of Clinical Endocrinology Metabolism 97:23802387. 
7. Latrofa F, Ricci D, Sisti E, Piaggi P, Nencetti C, Marino M, Vitti P 2016 Significance of Low Levels of Thyroglobulin Autoantibodies Associated with Undetectable Thyroglobulin After Thyroidectomy for Differentiated Thyroid Carcinoma. Thyroid 26:798-806.

8. Spencer C, Petrovic I, Fatemi S, LoPresti J 2014 Serum thyroglobulin (Tg) monitoring of patients with differentiated thyroid cancer using sensitive (second-generation) immunometric assays can be disrupted by false-negative and false-positive serum thyroglobulin autoantibody misclassifications. J.Clin Endocrinol.Metab 99:4589-4599.

9. Netzel BC, Grebe SK, Carranza Leon BG, Castro MR, Clark PM, Hoofnagle AN, Spencer CA, Turcu AF, Algeciras-Schimnich A 2015 Thyroglobulin (Tg) Testing Revisited: Tg Assays, TgAb Assays, and Correlation of Results With Clinical Outcomes. J.Clin Endocrinol.Metab 100:E1074-E1083.

10. Weigle WO High GJ 1967 The behavior of autologous thyroglobulin in the circulation of rabbits immunized with either heterologous or altered homologous thyroglobulin. J.Immunol 98:1105-1114.

11. Uller RP Van Herle AJ 1978 Effect of therapy on serum thyroglobulin levels in patients with Graves' disease. J.Clin Endocrinol.Metab 46:747-755.

12. Gardner DF, Rothman J, Utiger RD 1979 Serum thyroglobulin in normal subjects and patients with hyperthyroidism due to Graves' disease: effects of T3, iodide, 131 and antithyroid drugs. Clin Endocrinol.(Oxf) 11:585-594.

13. Feldt-Rasmussen U, Bech K, Date J, Petersen PH, Johansen K 1982 A prospective study of the differential changes in serum thyroglobulin and its autoantibodies during propylthiouracil or radioiodine therapy of patients with Graves' disease. Acta Endocrinol.(Copenh) 99:379-385.

14. Chiovato L, Fiore E, Vitti P, Rocchi R, Rago T, Dokic D, Latrofa F, Mammoli C, Lippi F, Ceccarelli C, Pinchera A 1998 Outcome of thyroid function in Graves' patients treated with radioiodine: role of thyroid-stimulating and thyrotropin-blocking antibodies and of radioiodine-induced thyroid damage. J.Clin.Endocrinol.Metab 83:40-46. 
15. Baloch Z, Carayon P, Conte-Devolx B, Demers LM, Feldt-Rasmussen U, Henry JF, LiVosli VA, Niccoli-Sire P, John R, Ruf J, Smyth PP, Spencer CA, Stockigt JR 2003 Laboratory medicine practice guidelines. Laboratory support for the diagnosis and monitoring of thyroid disease. Thyroid 13:3-126.

16. Spencer CA LoPresti JS 2008 Measuring thyroglobulin and thyroglobulin autoantibody in patients with differentiated thyroid cancer. Nat.Clin Pract.Endocrinol Metab 4:223-233.

17. Latrofa F, Pichurin P, Guo J, Rapoport B, McLachlan SM 2003 Thyroglobulinthyroperoxidase autoantibodies are polyreactive, not bispecific: analysis using human monoclonal autoantibodies. J.Clin.Endocrinol.Metab 88:371-378.

18. Latrofa F, Phillips M, Rapoport B, McLachlan SM 2004 Human monoclonal thyroglobulin autoantibodies: epitopes and immunoglobulin genes. J.Clin.Endocrinol.Metab 89:5116-5123.

19. Latrofa F, Ricci D, Vitti P, Prinzis A, Cambuli VM, Ghiani M, Pilia S, Carta D, Loche S, Pinchera A, Mariotti S 2010 Characterization of thyroglobulin epitopes in Sardinian adults and juveniles with Hashimoto's thyroiditis: evidence against a major effect of age and genetic background on B-cell epitopes. Clin Endocrinol (Oxf) 73:110-113.

20. Latrofa F, Fiore E, Rago T, Antonangeli L, Montanelli L, Ricci D, Provenzale MA, Scutari M, Frigeri M, Tonacchera M, Vitti P 2013 lodine contributes to thyroid autoimmunity in humans by unmasking a cryptic epitope on thyroglobulin. J.Clin Endocrinol.Metab 98:E1768-E1774.

21. Latrofa F, Ricci D, Grasso L, Vitti P, Masserini L, Basolo F, Ugolini C, Mascia G, Lucacchini A, Pinchera A 2008 Characterization of thyroglobulin epitopes in patients with autoimmune and non-autoimmune thyroid diseases using recombinant human monoclonal thyroglobulin autoantibodies. Journal of Clinical Endocrinology Metabolism 93:591-596. 
22. Latrofa F, Ricci D, Montanelli L, Altea MA, Pucci A, Pinchera A, Vitti P 2012 Thyroglobulin autoantibodies of patients with subacute thyroiditis are restricted to a major B cell epitope. J Endocrinol Invest 35:712-714.

23. Spencer CA, Bergoglio LM, Kazarosyan M, Fatemi S, LoPresti JS 2005 Clinical impact of thyroglobulin ( $\mathrm{Tg}$ ) and $\mathrm{Tg}$ autoantibody method differences on the management of patients with differentiated thyroid carcinomas. Journal of Clinical Endocrinology Metabolism 90:5566-5575.

24. Latrofa F, Ricci D, Montanelli L, Rocchi R, Piaggi P, Sisti E, Grasso L, Basolo F, Ugolini C, Pinchera A, Vitti P 2012 Thyroglobulin autoantibodies in patients with papillary thyroid carcinoma: comparison of different assays and evaluation of causes of discrepancies. Journal of Clinical Endocrinology Metabolism 97:3974-3982.

25. Schneider AB Pervos R 1978 Radioimmunoassay of human thyroglobulin: effect of antithyroglobulin autoantibodies. J.Clin Endocrinol.Metab 47:126-137.

26. Mariotti S, Cupini C, Giani C, Lari R, Rolleri E, Falco A, Marchisio M, Pinchera A 1982 Evaluation of a solid-phase immunoradiometric assay (IRMA) for serum thyroglobulin: effect of anti-thyroglobulin autoantibody. Clin Chim.Acta 123:347-355.

27. Azmat U, Porter K, Senter L, Ringel MD, Nabhan F 2017 Thyroglobulin Liquid Chromatography-Tandem Mass Spectrometry Has a Low Sensitivity for Detecting Structural Disease in Patients with Antithyroglobulin Antibodies. Thyroid 27:74-80.

28. Spencer CA 2011 Clinical Utility of Thyroglobulin Antibody (TgAb) Measurements for Patients with Differentiated Thyroid Cancers (DTC). Journal of Clinical Endocrinology Metabolism 96:3615-3627.

29. Latrofa F, Ricci D, Montanelli L, Piaggi P, Mazzi B, Bianchi F, Brozzi F, Santini P, Fiore E, Marino M, Tonacchera M, Vitti P 2014 Thyroglobulin autoantibodies switch to immunoglobulin (Ig)G1 and IgG3 subclasses and preserve their restricted epitope pattern after 131 l treatment for Graves' hyperthyroidism: the activity of autoimmune disease 
influences subclass distribution but not epitope pattern of autoantibodies. Clin Exp.Immunol 178:438-446.

30. Lo Gerfo P, Li Volsi V, Colacchio D, Feind C 1978 Thyroglobulin production by thyroid cancers. J.Surg.Res. 24:1-6.

31. Feldt-Rasmussen U, Petersen PH, Nielsen H, Date J, Madsen CM 1978 Thyroglobulin of varying molecular sizes with different disappearance rates in plasma following subtotal thyroidectomy. Clin Endocrinol.(Oxf) 9:205-214.

32. Izumi M, Kubo I, Taura M, Yamashita S, Morimoto I, Ohtakara S, Okamoto S, Kumagai LF, Nagataki S 1986 Kinetic study of immunoreactive human thyroglobulin. J.Clin Endocrinol.Metab 62:410-412.

33. Hocevar M, Auersperg M, Stanovnik L 1997 The dynamics of serum thyroglobulin elimination from the body after thyroid surgery. Eur.J.Surg.Oncol. 23:208-210.

34. Giovanella L, Ceriani L, Maffioli M 2010 Postsurgery serum thyroglobulin disappearance kinetic in patients with differentiated thyroid carcinoma. Head Neck 32:568-571.

35. Ikekubo K, Pervos R, Schneider AB 1980 Clearance of normal and tumor-related thyroglobulin from the circulation of rats: role of the terminal sialic acid residues. Metabolism 29:673-681.

36. Consiglio E, Salvatore G, Rall JE, Kohn LD 1979 Thyroglobulin interactions with thyroid plasma membranes. The existence of specific receptors and their potential role. J.Biol.Chem. 254:5065-5076.

37. Brix K, Wirtz R, Herzog V 1997 Paracrine interaction between hepatocytes and macrophages after extrathyroidal proteolysis of thyroglobulin. Hepatology 26:1232-1240.

38. Bruhns P 2012 Properties of mouse and human IgG receptors and their contribution to disease models. Blood 119:5640-5649. 


\section{Table 1}

Changes in concentrations of thyroid hormones and TSH, levels of TPOAb and TRAb and thyroid volume after ${ }^{131}$ I treatment for GD.

Data at the time of ${ }^{131}$ I treatment (day 0) (30 patients); follow-up at 15 days (25 patients), 30 days (28 patients), 45 days (24 patients), 60 days (24 patients), 75 days (21 patients) and 90 days (27 patients) is reported.

No patient received levothyroxine or methimazole at day 0 and day 15.1 patient was taking LT4 at day 30, 1 patient was taking methimazole and 3 patients were taking LT4 at day 45, 3 patients were on methimazole and 9 patients on LT4 at day 60, 2 patients were treated with methimazole and 18 patients with LT4 at day 75, 21 patients were on LT4 at day 90.

\begin{tabular}{|c|c|c|c|c|c|c|c|}
\hline Day & $\mathbf{0}$ & $\mathbf{1 5}$ & $\mathbf{3 0}$ & $\mathbf{4 5}$ & $\mathbf{6 0}$ & $\mathbf{9 0}$ & \\
\hline FT4 $(\mathrm{pg} / \mathrm{mL})$ & $11.1 \pm 4.6$ & $11.2 \pm 8.3$ & $9.6 \pm 4.2$ & $7.3 \pm 5.7$ & $6.5 \pm 4.7$ & $9.0 \pm 4.3$ & $10.7 \pm 6.4$ \\
\hline FT3 $(\mathrm{pg} / \mathrm{mL})$ & $4.9 \pm 4.5$ & $3.7 \pm 1.3$ & $3.5 \pm 0.85$ & $3.0 \pm 1.6$ & $2.6 \pm 1.3$ & $2.9 \pm 1.1$ & $3.1 \pm 1.0$ \\
\hline TSH $(\mu \mathrm{U} / \mathrm{mL})$ & $0.06 \pm 2.1$ & $0.01 \pm 1.4$ & $0.48 \pm 3.6$ & $5.02 \pm 18.5$ & $7.4 \pm 27.0$ & $10.7 \pm 26.5$ & $8.2 \pm 21.2$ \\
\hline TPOAb $(\mathrm{IU} / \mathrm{mL})$ & $76.0 \pm 252.0$ & $84.0 \pm 186.0$ & $76.0 \pm 171.0$ & $73.0 \pm 157.0$ & $185.0 \pm 241.0$ & $380.0 \pm 668.0$ & $662.0 \pm 616.0$ \\
\hline TRAb $(\mathrm{IU} / \mathrm{mL})$ & $4.9 \pm 14.6$ & $4.6 \pm 12.1$ & $5.1 \pm 11.3$ & $6.3 \pm 16.9$ & $9.0 \pm 44.1$ & $12.3 \pm 33.1$ & $14.7 \pm 52.6$ \\
\hline Thyroid volume $(\mathrm{mL})$ & $17.0 \pm 9.5$ & - & $11.5 \pm 6.0$ & - & $9.0 \pm 5.3$ & - \\
\hline
\end{tabular}




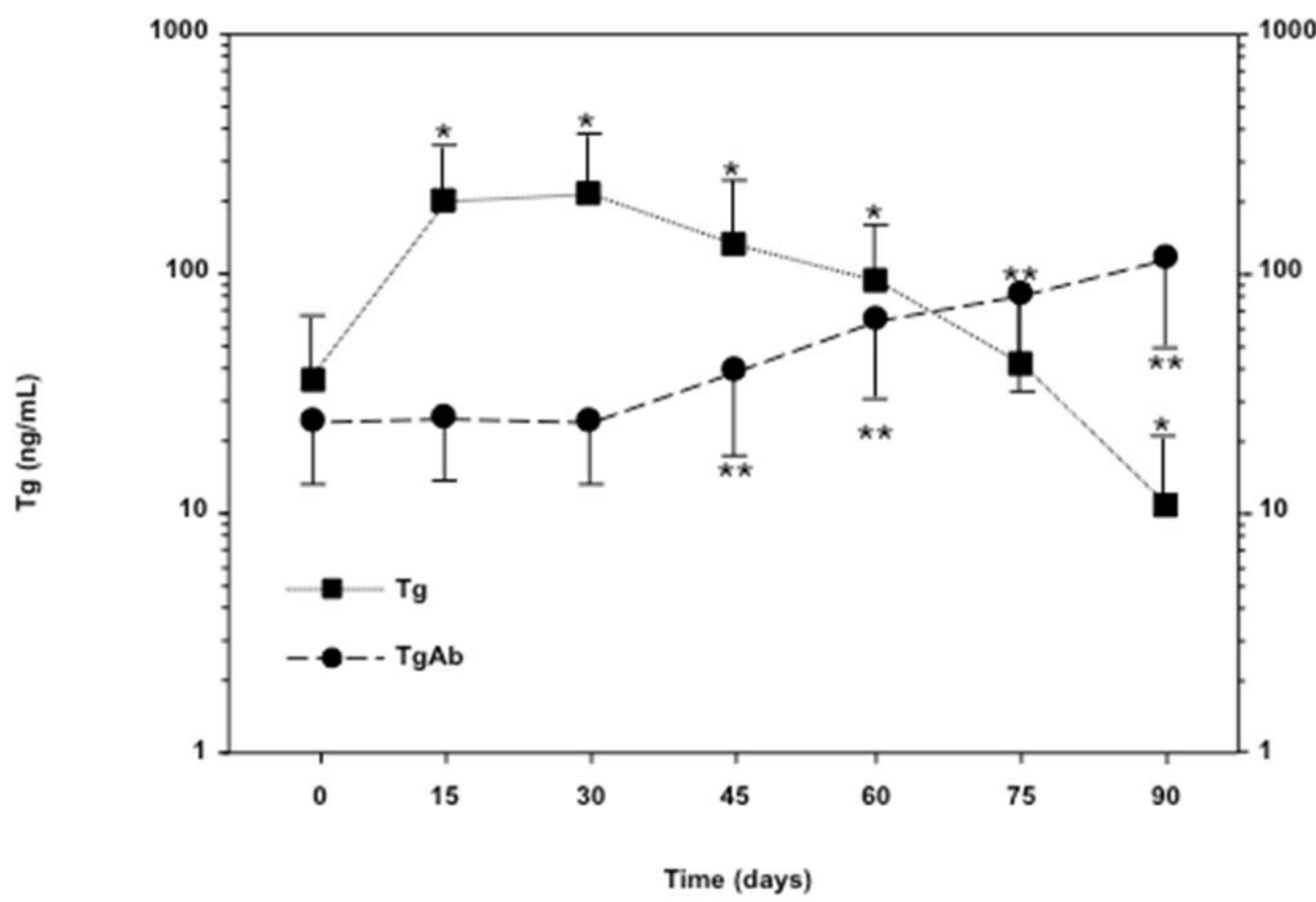

Figure 1. Changes in Tg concentrations and TgAb levels in patients with Graves' hyperthyroidism after 131 l treatment.

Day 0: 30 patients, day 15: 25 patients, day 30: 28 patients, day 45: 24 patients, day 60: 24 patients, day 75: 21 patients, day 90: 27 patients.

$* p<0.05$ vs $\operatorname{Tg}$ concentrations at day 0 ( $p<0.001$ at day 15 , day 30 and $45 ; p=0.001$ at day 60 and day 90$)$.

** $p<0.05$ vs TgAb levels at day $0(p=0.02$ at day $45 ; p<0.001$ at day 60 , day 75 and day 90). Geometric means with $95 \% \mathrm{Cl}$ are shown. 


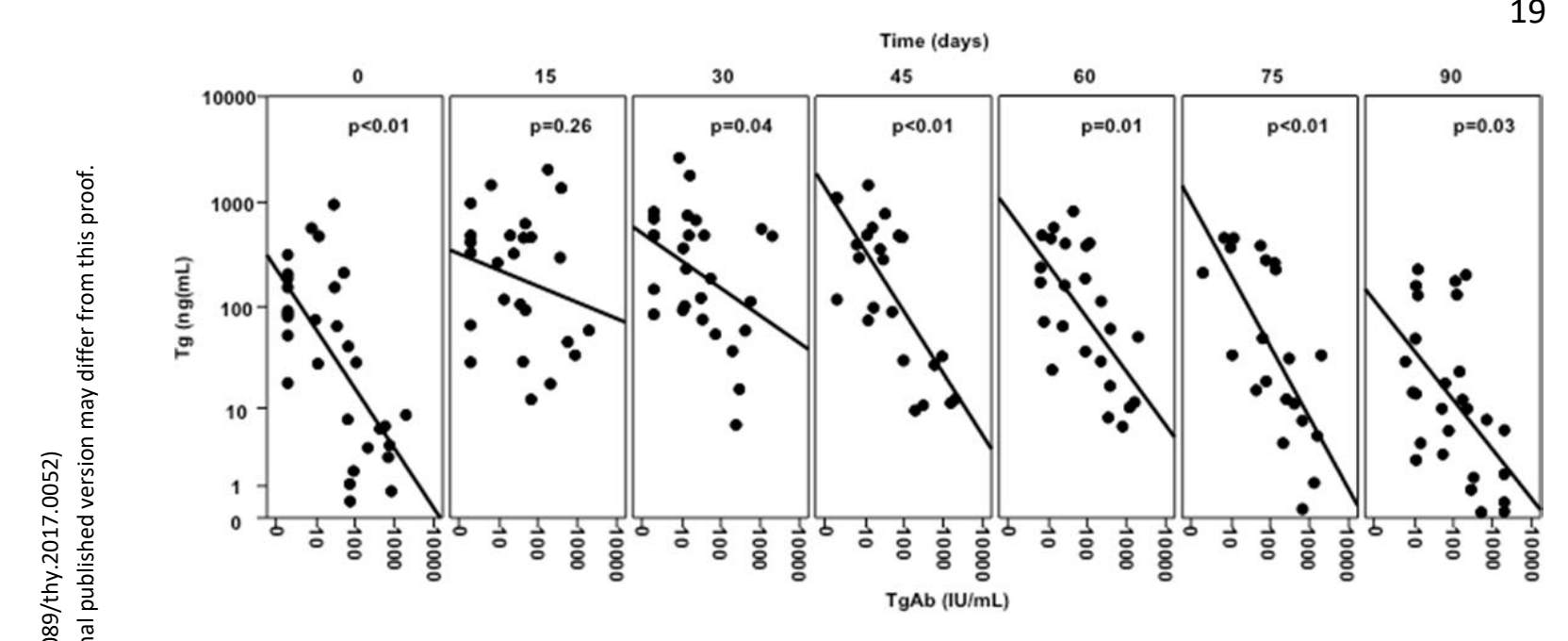

Figure 2. Correlations between TgAb levels and Tg concentrations in patients with Graves' hyperthyroidism after 131 l treatment.

Day 0: 30 patients, day 15: 25 patients, day 30: 28 patients, day 45: 24 patients, day 60: 24 patients, day 75: 21 patients, day 90: 27 patients. 


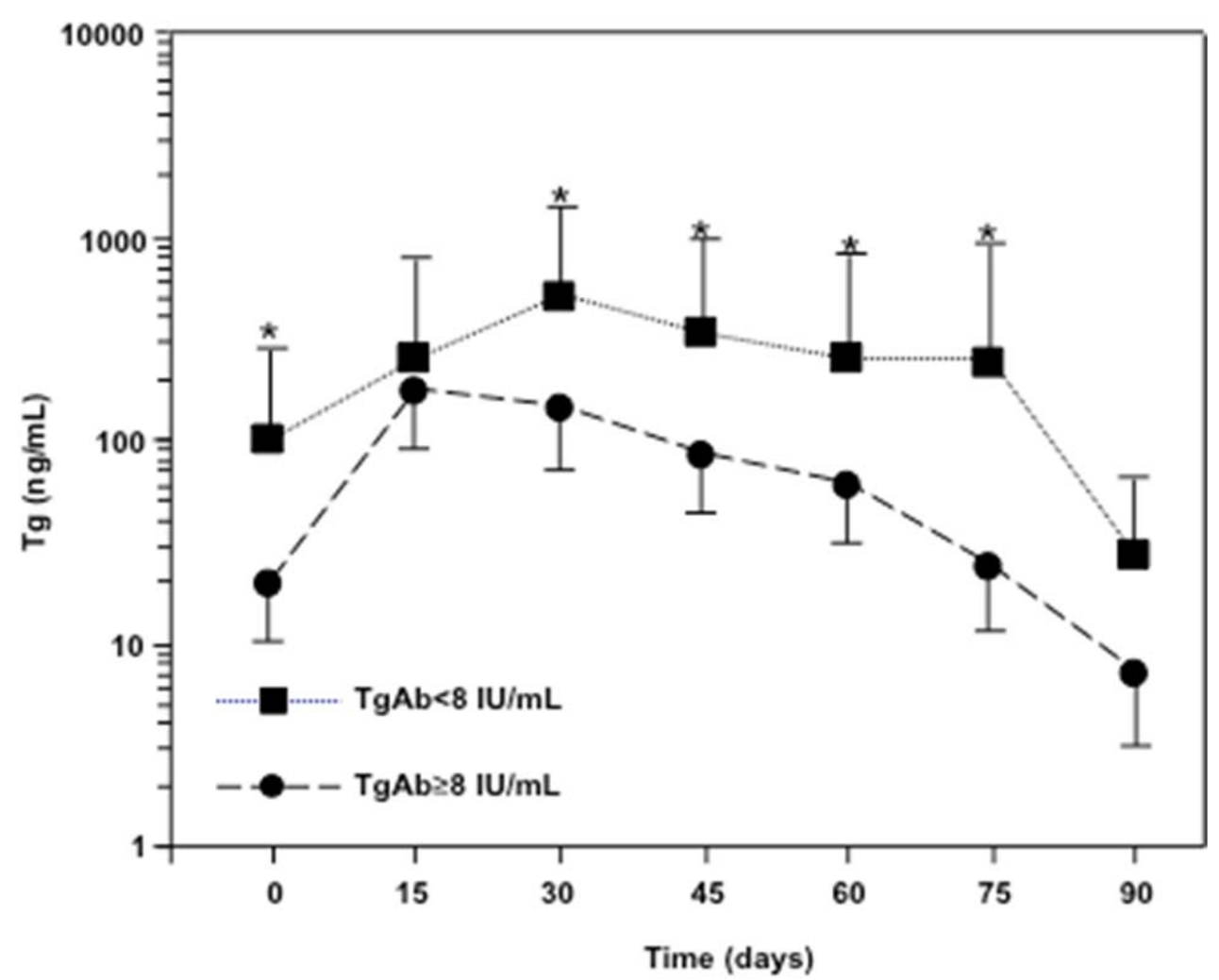

Figure 3. Changes in Tg concentrations in patients with Graves' hyperthyroidism after 131I treatment according to initial TgAb status: undetectable $(<8 \mathrm{IU} / \mathrm{mL})(9$ patients) or detectable ( $\geq 8 \mathrm{IU} / \mathrm{mL}$ ) (21 patients).

* $p<0.05$ between the two groups $(p=0.01$ at day $0 ; p=0.04$ at day 30 , day 45 and day 60 ; $p=0.003$ at day 75$)$.

Geometric means with $95 \% \mathrm{Cl}$ are shown. 


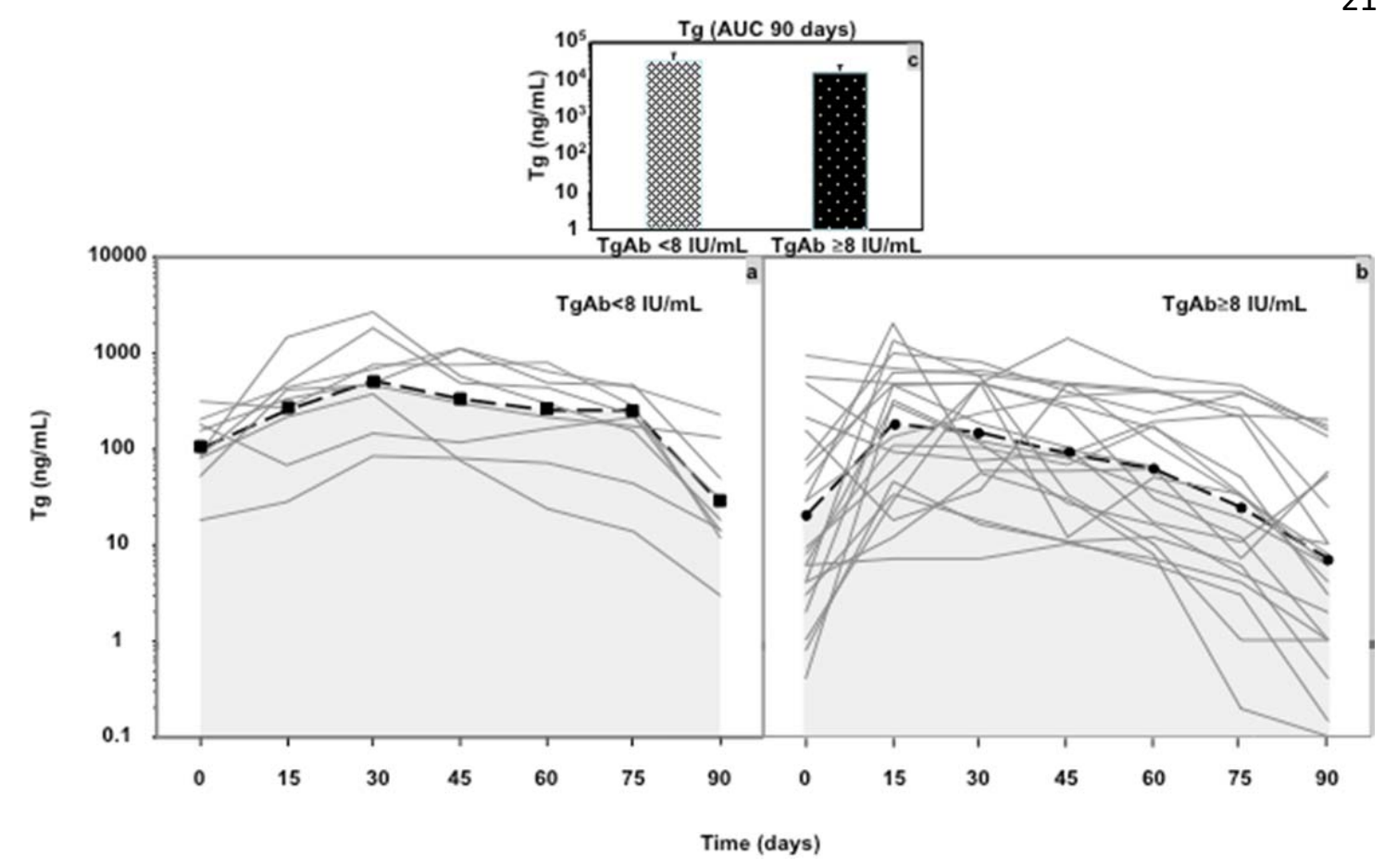

Figure 4. Individual and overall changes in Tg concentrations in patients with Graves' hyperthyroidism after 131 l treatment according to initial TgAb status: undetectable $\operatorname{TgAb}$ $(<8 \mathrm{IU} / \mathrm{mL})(\mathrm{a})$ or detectable $\operatorname{TgAb}(\geq 8 \mathrm{IU} / \mathrm{mL})(\mathrm{b})$. Tg concentrations of single patients (continuous thin lines) and overall Tg concentrations (discontinuous thick lines) are shown. Number of patients with undetectable TgAb: 9 at day 0,7 at day 15, 9 at day 30, 8 at day 45,5 at day 60, 3 at day 75, 9 at day 90. Number of patients with detectable TgAb: 21 at day 0,18 at day 15,19 at day 30,16 at day 45,19 at day 60,18 at day 75, 18 at day 90. $p<0.001$ by mixed models.

C: median of AUC of Tg concentrations in patients with undetectable TgAb vs. patients with detectable $\operatorname{TgAb}(p=0.02)$. Mean with $95 \% \mathrm{Cl}$ are shown. 